EESTI NSV TEADUSTE AKADEEMIA TOIMETISED. V KOIDE

BIOLOOGILINE SEERIA. 1956, NR. 4

ИЗВЕСТИЯ АКАДЕМИИ НАУК ЭСТОНСКОИ ССР. ТОМ V

СЕРИЯ БИОЛОГИЧЕСКАЯ. 1956, № 4

\title{
MIKROELEMENTIDE SISALDUS JA MIKROVÄETISTE EFEKTIIVSUS MÕNEDES EESTI NSV SOOMULDADES
}

\section{H. MICHELSON}

Nõukogude Liidu kolhooside ja sovhooside tootmispraktikas leiavad mikroväetised järjest laialdasemat kasutamist, Eesti NSV tingimustes on nendele aga seni võrdlemisi vähe tähelepanu pööratud. Eesti NSV Teaduste Akadeemia Taimekasvatuse Instituudis alustati mikroelementide uurimist 1952. aastal, et selgitada tähtsamate mikroelementide - vase, boori, mangaani ja koobalti sisaldust ning mikroväetiste efektiivsust vastavates mullaerimites. Kuna Eesti NSV-s tehakse pidevalt maaparanduslikke töid suurte soomassiivide ulatuses ja seni puudusid andmed tähtsamate mikroelementide sisaldusest soomuldades, alustati mikroelementide sisalduse uurimist lähemas tulevikus kuivendamisele määratud tähtsamates soomassiivides. Valiti välja kuus suuremat soomassiivi ja võeti igaühest (6-7 prooviaugust) keskmised mullaproovid $0-40 \mathrm{~cm}$ sügavusest. Nendes proovides määrati $\mathrm{pH}$, tuhasisaldus ning mikroelementide — vase, boori, mangaani ja koobalti sisaldus. Peale Lôuna- ja Kesk-Eesti soomassiivide uuriti vastavalt ka mõningaid Põhja-Eesti sooalasid.

Mikroelementide sisalduse määramised teostati NSV Liidu Teaduste Akadeemia V. I. Vernadski nimelise Geokeemia ja Analüütilise Keemia Instituudi poolt esitatud metoodika kohaselt $\left({ }^{1}\right)$. Omastatava vase sisaldus on määratud $1 \mathrm{n} \mathrm{HCl}$ leotises dietüülditiokarbamaat-meetodiga kolorimeetriliselt ja omastatava mangaani sisaldus, $0,5 \mathrm{n} \mathrm{H}_{2} \mathrm{SO}_{4}$ leotises persulfaatmeetodiga $\left({ }^{2}\right)$. Muldade liigitamisel on aluseks võetud A. Lillema poolt esitatud Eesti NSV mullastiku klassifikatsioon $\left({ }^{3}\right) .^{*}$

Alljärgnevalt esitatakse kuue suurema Kesk- ja Lõuna-Eesti soomassiivi lühike iseloomustus. Mullaproovide mikroelementide sisaldus antakse tabelis 1 .

Amme jõe basseini soomassiivi turvasmulla proovid võeti kohtadest nr. $1-7$ Kärkna raudteejaama lähedusest Pupastvere küla piirkonnast mõlemalt poolt külavaheteed. Maapinna üldine reljeef kujutab siin voortevahelist tasast ala. Mikroreljeef on enamuses mätlik, kohtades nr. 4 ja 5 tasane, kuivenduskraavidega. Turbakihi paksus keskmiselt $1,0-1,4 \mathrm{~m}$, kohas nr. 4 kuni 3 meetrit. Turvas on kohtades nr. 1-4 lehtsambla-tarna tüüpi, kohtades nr. 5 ja 7 tarna tüüpi madalsooturvas.

* Käesolevas töös on kasutatud mullaproovide kogumisel ja nende süstematiseerimisel ENSV TA Taimekasvatuse Instituudi teadusliku töötaja A. Lillema kaasabi. Lōuna- ja Kesk-Eesti soomassiividest mullaproovide valikul ja nende klassifitseerimisel on kaasabi osutanud EPA agrokeemia ja mullateaduse kateedri vanemõpetaja A. Piho ja ENSV TA Taimekasvatuse Instituudi teaduslik töötaja R. Kask. 
Pedja jõe basseini (Karja raba) soomassiivi mullaproovid (nr. 8-12 ja 14) võeti Rohe ja Lõppe küla vaheliselt maa-alalt. Peamine osa soomassiivist moodustab sookaskedega mätliku madalsoo tüüpi puisniiđu, millele lisanduvad kohati kadakad, männid, sanglepad ja paakspuud. Turvas on enamikus kõrrelis-tarna-metsa tüüpi, kohati esịneb turbas roo jäänuseid. Turbakihi tüsedus $1-2$ meetrit, aluspõh;aks sinine ibejas savi. Lagunemisaste enamikus kohtades $45-55 \%$, tõustes soomassiivi ääremaadel kuni $70 \%$-ni. Viimastel aastatel pole niidetud, mistõttu on üleni kattunud võsaga.

Põhjaka soomassiivi (Paide läheduses) mullaproovid (nr. 15-21) võeti Särgvere külanõukogu piirkonnast. Ulidiselt sügavast soomassiivist tõusevad $0,5-1,0$ hektari suurused õhukese turbakihiga $(40-50 \mathrm{~cm})$ paesaared. Maa on varem kasutusel olnud kultuurniiduna, mille saak on langenud loodusliku sooniidu tasemeni. Turbakihi tüsedus maksimaalselt $1 \mathrm{~m}$. Kohati asub paas $40 \mathrm{~cm}$ sügavuses. Põhjavee sügavus lahtiste kuivenduskraavide tõttu enamasti $50 \mathrm{~cm}$. Peamine osa soomassiivist moodustab sookase-lubika tüüpi madalsoo puisniidu, milles lubikas moodustab tiheda kamara. Turvas on päritolult enamikus kõrrelis-metsa tüüpi. Turba aluspõhjaks on sapropeel, millele järgneb sinine mudajas liiv, mis lasub moreenil. Valdavam osa soomassiivist on mullatüübilt madalsoomuld uhtliival lasuval, karbonaatsel moreenil.

Navesti jõe basseini (Mädasoo) turvasmullaproovid (nr. 22-28) vồti soomassiivist Vana-Venevere ja Unakvere küla piirkonnast Navesti jõe ülemjooksul. Soomassiiv valdavamas osas on siin mätlik madalsoo tüüpi vōsaniit. Turvas on kuni 2 m tüsedusega tarna-metsaturvas kohati pruunsambla jäänustega. Aluspôhjaks on sinine viirsavi. Pinnavesi $10-30 \mathrm{~cm}$ kõrgusel maapinnast, mis on tingitud Navesti jōe kõrgest veeseisust. Võsastumise tõttu on muutunud kasutamiskõlbmatuks. Viljakus on üldiselt väga madal.

Ôhne jõe basseini soomassiivi turvasmullaproovid (nr. $29-31$ ja $33-36$ ) võeti Leebiku asunduse piirkonnast mõlemalt poolt jõge. Leebiku jõe lamm on jõe iga-aastase üleujutuse tagajärjel põllumajanduslikult vähekasutatav maa. Varem on ta olnud kultuuristatud ja kôrge saagiga niit. Joe-äärsetes osades on soostunud mudaja lammimullaga mätlik heinamaa, -mille turbakihi tüsedus on 1,0-1,6 meetrit, aluspõhjaks peenliiv. Pealmises osas on ülekaalus tarnaturvas, sügavamal esineb puujäänuseid. Jõest kaugemates osades kasvab soomassiivil lodumets, milles turbakihi tüsedus on üle 3 meetri. Turbakihis domineerib metsaturvas sinisavi aluspōhjal.

Väike-Emajõe basseini Korva luha massiivi mullaproovid (nr. 37-42) võeti Laatre ja Tagula vahelise tee piirkonnast Valga rajoonis. Luht on seni kasutusel olnud loodusliku kõrgesaagilise heinamaana. Turbakihi tüsedus $0,6-1,3 \mathrm{~m}$. Ulekaalus on lehtsambla-tarnaturvas, mis kohati mudajas. Aluspõhjana esineb uhtsavi.

Mikroväetiste efektiivsuse kindlaksmääramiseks võeti eelnimetatuđ soomassiivide kolmest soost - Amme jõe piirkonnast ülesharitud soo põllult, Põhjaka soo niidult ja Ohne jõe lammilt Leebiku piirkonnast heinamaalt turvasmullad $0-40 \mathrm{~cm}$ sügavuselt, segati põhjalikult ja sõeluti läbi ühe $\mathrm{cm}$ suuruste avadega sõela. Nende muldadega täideti parafineeritud savianumad, kusjuures igasse anumasse mahutati $7 \mathrm{~kg}$ mulda. Taimede kastmine toimus destilleeritud veega kindlas koguses kuni $60 \%$ täielikust mulla veemahutavusest. Põhiväetisena anti ühe $\mathrm{kg}$ mulla kohta $0,07 \mathrm{~g} \mathrm{P}_{2} \mathrm{O}_{5}$ ja $0,09 \mathrm{~g} \mathrm{~K} \mathrm{~K}_{2} \mathrm{O}$ keemiliselt puhaste ühendite $\mathrm{KH}_{2} \mathrm{PO}_{4}$ ja $\mathrm{KCl}$ näol. Mikroväetistena kasutati keemiliselt puhtaid mikroelementide ühendeid - ühe $\mathrm{kg}$ turvasmulla kohta $10 \mathrm{mg}$ vasksulfaati, $7 \mathrm{mg}$ mangaansulfaati ja $6 \mathrm{mg}$ booraksit. Mainitud annuste suurendamine vegetatsioonikatsetes märgatavat 
Kesk- ja Lõuna-Eesti soomassiivide turvasmulla mikroelementide sisaldus

\begin{tabular}{|c|c|c|c|c|c|c|c|}
\hline 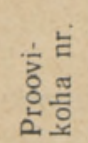 & $\bar{\Sigma}$ & 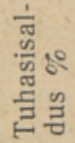 & 己̋ & ن를 & 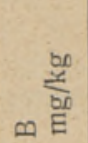 & $\sum_{\Sigma}^{5} 80$ & Mulla iseloomustus \\
\hline
\end{tabular}

A m me jõe soomassiiv

\begin{tabular}{|c|c|c|c|c|c|c|}
\hline 5,9 & 14,0 & 7,5 & 0,9 & 10,5 & 0,044 & Kōdu-madalsoomuld uhtsavil \\
\hline 5,5 & 11,0 & 3,8 & 1,0 & 6,3 & 0,043 & $\begin{array}{l}\text { Turvas-kōdu-madalsoomuld merglilisel } \\
\text { liivsavil }\end{array}$ \\
\hline 5,4 & 11,1 & 3,4 & $-0,5$ & 7,2 & 0,016 & Turvas-kõdu-madalsoomuld uhtsavil \\
\hline 5,4 & 10,7 & 3,0 & 1,2 & 8,1 & 0,078 & Kōdu-madalsoomuld \\
\hline 5,4 & 7,5 & 1,6 & 0,6 & 6,9 & 0,005 & Turvas-madalsoomuld \\
\hline 5,7 & 12,9 & 2,9 & 0,8 & 10,5 & 0,018 & Madalsoomuld \\
\hline 5,9 & 10,4 & 1,8 & 1,3 & 60 & 0,023 & Turvas-kõdu-madalsoomuld \\
\hline
\end{tabular}

P e d j a jõe soomassiiv

\begin{tabular}{r|r|r|r|r|r|r|}
8 & 5,4 & 11,8 & 3,3 & 0,5 & 7,8 & 0,046 \\
9 & 5,6 & 14,9 & 3,3 & 0,7 & 9,9 & 0,052 \\
10 & 5,6 & 17,6 & 10,4 & 1,2 & 6,0 & 0,034 \\
11 & 5,0 & 13,6 & 3,4 & 0,7 & 4,8 & 0,008 \\
12 & 4,8 & 10,4 & 5,0 & 0,8 & 5,7 & 0,008 \\
14 & 5,8 & 12,2 & 11,0 & 0,6 & 11,6 & 0,008
\end{tabular}

Turvas-ködu-madalsoomuld uhtsavil

Turvas-kōdu-madalsoomuld uhtsavil

Kōdu-madalsoomuld ibejal uhtsavil

Turvas-kõdu-madalsoomuld

Turvas-kōdu-madalsoomuld

Kõdu-madalsoomuld

Põ h j a k a soo

\begin{tabular}{r|r|r|r|r|r|r|}
15 & 5,7 & 13,0 & 4,8 & 0,8 & 9,6 & 0,006 \\
16 & 5,4 & 12,8 & 7,9 & 0,8 & 9,0 & 0,005 \\
17 & 6,1 & 70,5 & 2,4 & 2,6 & 10,0 & 0,014 \\
18 & 5,3 & 14,2 & 7,5 & 1,3 & 8,7 & 0,011 \\
19 & 5,1 & 13,8 & 7,4 & 0,6 & 3,9 & 0,023 \\
20 & 3,5 & 9,7 & 5,8 & 0,6 & 0,2 & 0,002 \\
21 & 6,2 & - & 2,7 & 0,4 & 14,4 & 0,145
\end{tabular}

Kõdu-madalsoomuld uhtliival lasuval sapropeelil

Kõdu-madalsoomuld uhtliival lasuval karbonaatsel moreenil

Küllastunud ja turvastunud kamargleimuld pael lasuval karbonaatsel savil

Kōdu-madalsoomuld karbonaatsel moreenil

Kõdu-madalsoomuld tolmjal uhtsavil

Turvas-kõdu-rabasoomuld

Küllastunud ja turvastunud kamargleimuld karbonaatsel savil 


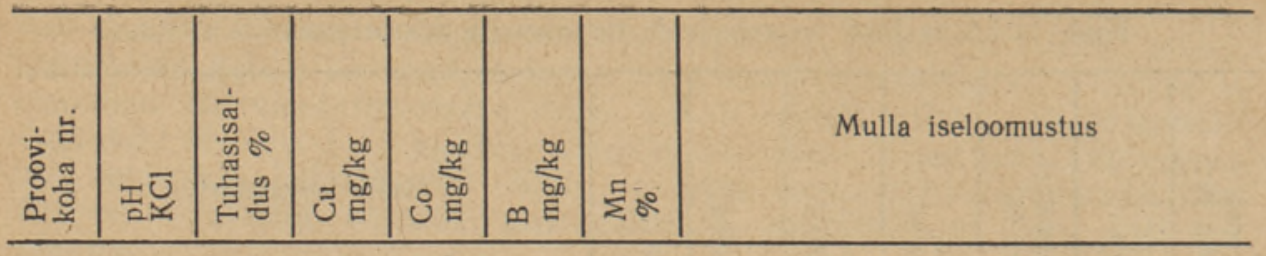

$\mathrm{N}$ avesti jõe soomassiiv (Mädasoo)

\begin{tabular}{l|r|r|r|r|r|r|l}
22 & 5,2 & 11,0 & 4,8 & 0,8 & 3,0 & 0,013 & Turvas-ködu-madalsoomuld uhtsavıl \\
23 & 5,2 & 7,8 & 2,4 & 0,7 & 0,9 & 0,011 & Turvas-rabasoomuld \\
24 & 5,3 & 8,0 & 1,2 & 0,5 & 0,1 & 0,011 & Turvas-rabasoomuld \\
25 & 5,6 & 6,5 & 3,6 & 1,0 & 3,0 & 0,060 & Turvas-madalsoomuld uhtsavil \\
26 & 5,6 & 6,7 & 2,5 & 0,7 & 1,0 & 0,060 & Turvas-madalsoomuld uhtsavil \\
27 & 5,6 & 5,8 & 2,9 & 0,7 & 4,8 & 0,050 & Turvas-madalsoomuld uhtsavil \\
28 & 5,7 & 6,7 & 2,8 & 1,2 & 2,4 & 0,042 & Turvas-madalsoomuld uhtsavil
\end{tabular}

O hne jõe soomassiiv (Leebiku)

\begin{tabular}{r|r|r|r|r|r|r|}
29 & 5,4 & 23,9 & 4,8 & 0,8 & 13,2 & 0,040 \\
30 & 5,8 & 14,9 & 2,4 & 0,7 & 6,8 & 0,100 \\
31 & 6.0 & 17,0 & 1,2 & 0,5 & 8,1 & 0,026 \\
33 & 5,1 & 11,7 & 5,6 & 1,0 & 7,2 & 0,008 \\
34 & 5,1 & 28,3 & 2,5 & 0,7 & 27,6 & 0,018 \\
35 & 6,2 & 16,3 & 2,9 & 0,7 & 23,4 & 0,043 \\
36 & 7,4 & 30,0 & 2,8 & 1,2 & 21,6 & 0,600
\end{tabular}

Mudajas lammi-kõdu-madalsoomuld

Kõdu-madalsoomuld

Kōdu-madalsoomuld uhtsavil

Turvas-kōdu-rabasoomuld

Mudajas lammi-kõdu-turvas-madalsoomuld

Mudajas lammi-kōdu-turvas-madalsoomuld

Küllastunud ja turvastunud kamar. gleimuld ibejal saviliival

Väike-Emajōe soomassiiv (Korva luht)

\begin{tabular}{l|c|c|c|c|c|c|}
37 & 5,4 & 23,0 & 1,5 & 1,2 & 22,2 & 0,024 \\
38 & 5,4 & 14,3 & 1,8 & 0,6 & 14,8 & 0,035 \\
39 & 5,2 & 10,2 & 3,5 & 0,9 & 12,6 & 0,014 \\
40 & 5,1 & 17,3 & 6,7 & 1,6 & 19,5 & 0,013 \\
41 & 5,2 & - & - & - & 15,6 & 0,030 \\
42 & 4,9 & - & 0,6 & 1,9 & 15,3 & 0,050
\end{tabular}

Mudajas lammi-turvas-kōdu-madalsoomuld uhtsavil

Lammi-turvas-kōdu-madalsoomuld uhtsavil

Turvas-kōdu-madalsoomuld tolmjal liivsavil

Mudajas lammi-turvas-kōdu-madalsoomuld uhtsavil

Mudajas lammi-kõdu-madalsoomuld uhtsavil

Mudajas lammi-turvas-kõdu-kamargleimuld uhtsavil 
positiivset möju viljasaagi suurenemisele enam ei avaldanud. Andmed vegetatsioonikatseteks kasutatud muldade mikroelementide sisalduse ja mikroväetistega saadud enamsaakide kohta on esitatud tabelis 3. Katsekultuurina kasutati kaera.

Põllumajanduslike kultuuride viljelemisel turvasmuldadel on suureks takistuseks vasepuudus mullas. A. O. Voinari poolt toodud andmeist NSV Liidu ulatuses selgub, et kui turvasmullas on vasesisaldus alla $6 \mathrm{mg}$ ühe kilo mulla kohta $\left(6 \cdot 10^{-4} \%\right)$, siis sellistel muldadel on taimede normaalne arenemine takistatud $\left({ }^{4}\right)$.

ENSV TA Maaparanduse ja Sookultuuri Instituudi Tooma katsebaasis on vaskväetise toimel saadud suuri saagitõususid $\left({ }^{5}\right)$. Kõrget saagitõusu vaskväetise toimel on võimalik saada ka kultuurkarjamaadel. A. Raidla andmeil on Tooma katsebaasi madalsool saadud kuivheina saagitõusu $74 \%\left({ }^{6}\right)$. Nagu vastavad analüüsid näitavad, on Tooma katsebaasi Kärde kultuurkarjamaa turvasmulla vasesisaldus $0-20 \mathrm{~cm}$ sügavuses keskmiselt $3,0 \mathrm{mg} / \mathrm{kg}$ ja omastatava vase sisaldus $0,25 \mathrm{mg} / \mathrm{kg}$.

Läti NSV tingimustes J. Peive poolt teostatud laiaulatuslike uurimuste alusel tuleb pidada põllumajanduslike kultuuride kasvatamisel turvasmuldadel $1 \mathrm{n}$ soolhappes lahustuva vase sisaldust mullas üle $5 \mathrm{mg} / \mathrm{kg}$ küllaldaseks, 3,0-5,0 mg/kg piirides keskmiseks, $1,0-3,0 \mathrm{mg} / \mathrm{kg}$ madalaks ja alla $1,0 \mathrm{mg} / \mathrm{kg}$ väga madalaks $\left({ }^{7}\right)$.

Eesti NSV territooriumilt kogutud soomullaproovide mikroelementide analüüsi resultaatidest (tabelid 1 ja 2 ) selgub, et seni läbiuuritud soomassiividest (kokku 50 proovikoha andmeil) on neis vasesisaldus $0,5-11 \mathrm{mg}$ piirides ühe kilo absoluutkuiva mulla kohta. Uksikute Kesk- ja Lõuna-Eesti soomassiivide järgi on vasesisaldus Amme jōe piirkonna soomuldades 1,6-7,5 mg, Pedja jõe basseinis 3,3-11 mg, Pōhjaka soos 2,4-7,9 mg, Navesti ning Ohne jōe basseinis $1,2-5,6 \mathrm{mg}$ ja Väike-Emajōe Korva luha soomuldades $0,6-6,7 \mathrm{mg}$ ühe $\mathrm{kg}$ absoluutkuiva mulla kohta. Põhja-Eesti vähemate sooalade vasesisaldus on 10 proovikoha analüüside andmeil 2,5—5,6 mg piirides, tõustes mõnedes kohtades kuni $8,7 \mathrm{mg} / \mathrm{kg}$.

Vase üldsisalduse pōhjal mullas ei saa veel otsustada vaskväetise vajaduse üle, vaid selleks tuleb selgitada, milline osa olemasolevast vasest on taimedele omastatav. Selleks käsitatakse uuritavat mulda 12 tunni vältel 1 n soolhappega ja määratakse selles lahustunud vask. Nagu esialgsed analüüsid näitavad, sisaldavad Eesti NSV turvasmullad $1 \mathrm{n}$ soolhappes lahustuvat vaske $0,1-3,5 \mathrm{mg}$ ühe kilo mulla kohta. Real juhtudel esineb meie sooaladel muldasid, milledes mikrokeemiliste analüüside põhjal võib järeldada vaskväetiste vähest efektiivsust, nagu see näiteks esineb Ônne jōe basseini turvasmullas, kus omastatava vase sisaldus oli $3,0 \mathrm{mg} / \mathrm{kg}$.

Turvasmuldadel teostatud vegetatsioonikatsetes kaeraga saadi kõige suurem terasaagi juurdekasv vaskväetise toimel - 40,1\% Põhjaka soo turvasmullal, milles vase üldsisaldus oli $6,0 \mathrm{mg} / \mathrm{kg}$ ja omastatava vase sisaldus $1,6 \mathrm{mg} / \mathrm{kg}$. Vähem oli saagi juurdekasv Amme jõe basseini soomullal $19,3 \%$, kusjuures vase üldsisaldus mullas oli $3,4 \mathrm{mg}$ ja omastatava vase sisaldus $1,2 \mathrm{mg} / \mathrm{kg}$. Saagi juurdekasv puudus üldse Ohne jõe lammilt pärinevas mullas, milles vase üldsisaldus oli $5,5 \mathrm{mg}$ ja omastatava vase sisaldus $3,0 \mathrm{mg} / \mathrm{kg}$.

M. D. Bahhulini poolt esitatud andmeil $\left({ }^{8}\right)$ on turvas- ja üldse huumusrikastes muldades vase omastatavus taimede poolt minimaalne mullareaktsiooni $\mathrm{pH}$ 5,5-6,5 juures. Mainitud asjaolu kajastub ka seni teostatud vegetatsioonikatsetes Eesti NSV turvasmuldadel, kus kõige suurema enamsaagi puhul Pōhjaka soomassiivi mulla $\mathrm{pH}$ oli 5,8 , madalama enamsaagiga Amme jōe basseini soomulla $\mathrm{pH}$ oli 5,5 ja üldse mitte enamsaaki andnud Ohne jõe lammi soomulla $\mathrm{pH}$ oli 5,0 . 
Põhja-Eesti kamar-karbonaatsete muldade valdkonnas asuvates soodes on kümnest soost võetud mullaproovide analüüside alusel (tabel 2) vasesisaldus üldiselt madal. Seda arvestades võib neil muldadel järeldada vaskväetise efektiivsust, sest siin enamikus esineb mullareaktsioon $\mathrm{pH}$ 5,5-6,0 piirides, mis raskendab mikroelemendi — vase omastatavust taimede poolt.

Kuigi soomuldadel leiavad üldist kasưtamist vaskväetised, on katseid tehtud ka boorväetistega. Eesti NSV tingimustes on selliseid katseid teostatud Maaparanduse ja Sookultuuri Instituudi katsebaasis Toomal keskmise lagunemisastmega madalsoomullal, kus boorväetis andis 1948. ja 1950. aastal roosa ristikuga keskmiselt 4,3 ts enamsaaki, kuna mõnel katseaastal enamsaaki ei esinenud $\left({ }^{9}\right)$.

Taimekasvatuse Instituudis teostatud analüüside andmed Eesti NSV soomuldades boorisisalduse kohta on esitatud tabelites $1^{*}$ ja 2 . Nagu nendest selgub, on seni kogutud ja läbitöötatud turvasmullaproovides boorisisaldus $0,2-27,6 \mathrm{mg} / \mathrm{kg}$ piirides. Kõige madalama boorisisaldusega nendest on mullad Navesti jõe basseinis (Mädasoo), kus boorisisaldus kõigub 0,1-4,8 $\mathrm{mg} / \mathrm{kg}$ piirides. Keskmise boorisisaldusega on Kesk-Eestis, Paide rajoonis asuv Pöhjaka soo, Amme jõe soomassiiv ja Pedja jõgikonna soomassiiv Karja raba piirkonnas. Köige kõrgema boorisisaldusega soomassiivid seni olemasolevail andmeil on Lõuna-Eestis Väike-Emajōe basseinis paiknev Korva luht, mille turvasmullas on leitud boori $12,6-22,2 \mathrm{mg} / \mathrm{kg}$ piirides, ja Ohne jõe basseini turvasmullad boorisisaldusega $6,8-27,6 \mathrm{mg} / \mathrm{kg}$ piirides.

Põhja-Eesti kamar-karbonaatmuldade valdkonnas paiknevate soode hulgas (tabel 2) on madala boorisisaldusega soid $(2,0-4,5 \mathrm{mg} / \mathrm{kg})$, kuid esineb ka keskmise boorisisaldusega turvasmuldasid $(7,5-10 \mathrm{mg} / \mathrm{kg})$.

Boorväetiste efektiivsuse kindlaksmääramiseks on kasutatud eelmainitud kolme turvasmulda, millede boorisisaldus on esitatud tabelis 3 . Nagu selgub, on Põhjaka soost päritolevas mullas boorisisaldus kõige madalam $5,0 \mathrm{mg} / \mathrm{kg}$. Siin andis boorväetiste kasutamine köige parema tulemuse keskmiselt 24,6\% terade enamsaaki katseanuma kohta. Boorisisalduse puhul $10 \mathrm{mg} / \mathrm{kg}$ ja enam ei ole väljavaateid boorväetise abil tõsta katsekultuuride saagikust, eriti sel juhul, kui mulla $\mathrm{pH}$ on alla 5,5. Seda kinnitavad ka läbiviidud vegetatsioonikatsed Amme jõe basseinist ja Ohne jõe lammilt päritoleva mullaga. Nendest esimese mulla boorisisaldus oli $10 \mathrm{mg} / \mathrm{kg}$ ja teisel mullal $18 \mathrm{mg} / \mathrm{kg}$. Nendel muldadel boorväetis kaera puhul enamsaaki ei põhjustanud.

Mangaanisisalduse kohta turvasmuldades, samuti ka mangaanväetiste kasutamisvõimaluste kohta puudusid seni lähemad andmed. Nagu eespool toodud Eesti NSV turvasmuldade analüüside andmeist selgub, esinevad Eesti NSV turvasmuldade mangaanisisalduses suured kôikumised. Eespool mainitud soomassiivide hulgas esines kohti, kus mangaani üldsisaldus oli $0,002-0,005 \%$ piirides. Neid muldasid tuleb pidada kõige mangaanivaesemateks. Enamikus proovivõtmise kohtades oli mangaanisisaldus 0,025 $-0,050 \%$ piirides, mida tuleb pidada meie mullastikus keskmiseks sisalduseks. Kõige kõrgemaks mangaanisisalduseks oli Amme jõe piirkonna soomassiivis $0,078 \%$, Pedja jõe basseini soos $0,052 \%$, Põhjaka soos $0,145 \%$ ja Ohne jõe lammis ühes proovivõtmise kohas $0,6 \%$. Viimast sisaldust tuleb pidada Eesti NSV mullastiku tingimustes kõige mangaanirikkamaks. Selliseid kõrge mangaanisisaldusega muldasid esineb piiratud ulatuses, sōltuvalt erilistest kohalikest mullastikutingimustest.

Kuivõrd mullas esinev mangaan on omastatav, saab kindlaks teha määramise teel. Selleks käsitatakse mulda ettenähtud meetodi kohaselt $\left({ }^{2}\right)$ $0,5 \mathrm{n}$ väävelhappega ja määratakse väävelhappelisse väljatõmbesse üleläi- 
Põhja-Eesti soomuldade mikroelementide sisaldus

Tabel 2

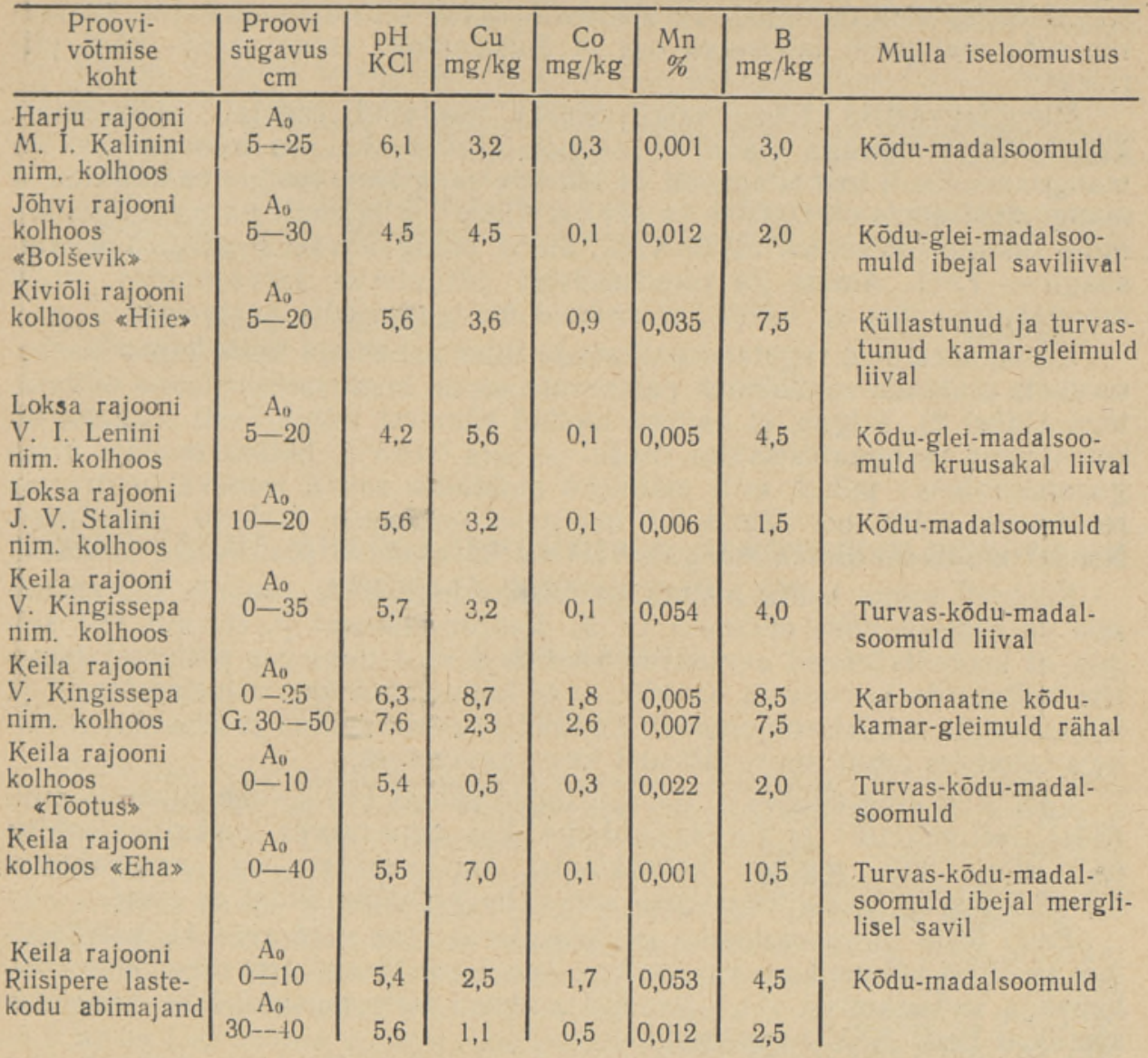

Vegetatsioonikatseteks kasutatud soomuldade mikroelementide Tabel 3 sisaldus ja mikroväetiste efektiivsus

\begin{tabular}{|c|c|c|c|c|c|c|c|}
\hline \multirow[b]{2}{*}{$\begin{array}{l}\text { Katsemulla } \\
\text { päritolu }\end{array}$} & \multicolumn{2}{|c|}{$\mathrm{Cu}$} & \multicolumn{2}{|c|}{$\mathrm{Mn}$} & \multirow{2}{*}{\begin{tabular}{|c} 
B \\
üld- \\
sisal- \\
dus \\
$\mathrm{mg} / \mathrm{kg}$
\end{tabular}} & \multirow[b]{2}{*}{$\begin{array}{l}\mathrm{pH} \\
\mathrm{KCl}\end{array}$} & \multirow[b]{2}{*}{$\begin{array}{c}\text { Mikroväetiste } \\
\text { efektiivsus } \\
\text { teraşaagile }\end{array}$} \\
\hline & $\begin{array}{l}\text { üld- } \\
\text { sisal- } \\
\text { dus } \\
\mathrm{mg} / \mathrm{kg}\end{array}$ & $\begin{array}{l}\text { omas- } \\
\text { tatav } \\
\mathrm{mg} / \mathrm{kg}\end{array}$ & $\begin{array}{l}\text { üld- } \\
\text { sisal- } \\
\text { dus } \\
\%\end{array}$ & $\begin{array}{c}\text { omas- } \\
\text { tatav } \\
\%\end{array}$ & & & \\
\hline $\begin{array}{l}\text { Amme jōe bas- } \\
\text { sein } \\
\text { (Tartu rajoon) }\end{array}$ & 3,4 & 1,2 & 0,060 & 0,040 & 10,7 & 5,5 & $\begin{array}{l}\text { Vask - } 19,3 \% \text { enam- } \\
\text { saaki } \\
\text { Mangaan - enamsaak } \\
\text { puudub } \\
\text { Boor - enamsaak } \\
\text { puudub }\end{array}$ \\
\hline $\begin{array}{l}\text { Pōhjaka soo } \\
\text { (Paide rajoon) }\end{array}$ & 6,0 & 1,6 & 0,007 & 0,004 & 5,0 & 5,8 & $\begin{array}{l}\text { Vask - } 40,1 \% \text { enam- } \\
\text { saaki } \\
\text { Mang2an - } 74,4 \% \\
\text { enamsaaki } \\
\text { Boor - 24,6\% enam- } \\
\text { saaki }\end{array}$ \\
\hline $\begin{array}{l}\text { Ohne jõe lamm } \\
\text { (Tōrva rajoon) }\end{array}$ & 5,5 & 3,0 & 0,041 & 0,036 & 18,0 & 5,0 & $\begin{array}{l}\text { Vask - enamsaak } \\
\text { puudub } \\
\text { Mangaan - } 7,6 \% \\
\text { enamsaaki } \\
\text { Boor - enamsaak } \\
\text { puudub }\end{array}$ \\
\hline
\end{tabular}


nud mangaani sisaldus. Nagu vastavad analüüsid näitavad, esineb meil soomuldades olev mangaan vōrdlemisi kergesti omastataval kujul, kusjuures suhe mangaani lahustuva osa ja üldsisalduse vahel on 55-95\% piirides.

Mangaanväetise toime selgitamiseks teostatud vegetatsioonikatsetest katsekultuuri kaeraga (tabel 3) selgub, et Põhjaka soo turvasmullal on mangaansulfaadi toimel saadud $74,4 \%$-line saagitõus, kusjuures katsemulla mangaanisisaldus oli $0,007 \%$ ja pH 5,8. Ohne jōe lammilt pärineval mullal, mille mangaanisisaldus oli $0,041 \%$, andis mangaanväetis madala enamsaagi - 7,6\%. Amme jõe soomassiivist päritolevas turvasmullas, mille mangaanisisaldus oli $0,06 \%$, ei andnud mangaanväetis enamsaaki.

Kõrvutades neid vegetatsioonikatsete tulemusi Põhja-Eesti kamar-karbonaatsete muldade valdkonnas paiknevate soode mangaanisisalduse näitajatega (tabel 2), selgub, et näitena toodud kümnest Põhja-Eesti sooalast on kuuel juhul mangaanisisaldus madal - alla $0,015 \%$. Sellise madala mangaanisisalduse puhul, eriti mainitud muldades sageli esineva neutraalse reaktsiooni tõttu, on olemasolev mangaan taimedele raskesti omastatav. Nendel muldadel annab mangaanväetiste kasutamine positiivseid tulemusi.

Koobalti toime kohta põllumajanduslike kultuuride saakide suurenemisele on üldiselt vähe andmeid. O. K. Kedrov-Zihmani jt. töödest ${ }^{\left({ }^{10}\right)}$ selgub, et koobaltväetised avaldavad soodsat toimet terve rea põllumajanduslike kultuuride kasvule ja saagile, eriti lubjastatud kamar-leetmuldadel ja lubjastamata madalsoomuldadel. Koobaltisisaldus mullas ja ühenduses sellega taimedes omab suurt tähtsust loomakasvatuses.

Läti NSV tingimustes J. Berzini tööde põhjal ( $\left.{ }^{11}\right)$ esineb liivastel muldadel, leetmuldadel ja turvasmuldadel, kus omastatava koobalti sisaldus on alla $2,0 \mathrm{mg} / \mathrm{kg}$, kevadkuudel kariloomade nn. "soohaigus». 2,3-2,5 mg/kg koobaltisisalduse korral haigusnähte enam ei esine.

Eesti NSV turvasmuldades on käesolevas töös määratud koobaltisisaldus analüüsi käigus koos vase mikrokeemilise määramisega rubeaanvesinikhappega sadestamisel $\left(^{1}\right)$. Saadud andmed iseloomustavad koobalti üldsisaldust Eesti NSV turvasmuldades.

Nagu tabelitest 1 ja 2 selgub, on enamikus kirjeldatavais soomassiivides koobaltisisaldus $0,1-1 \mathrm{mg}$ pirides ühe $\mathrm{kg}$ mulla kohta. Oksikutes soomassiivides, nagu Paide lähedases Põhjaka soos ja Põhja-Eesti soodes oli mõnes kohas koobaltit maksimaalselt 2,6 mg ühe kg mulla kohta. Kuna taimede poolt omastatavad koobaltikogused on veelgi piiratumad, tuleb Eesti NSV soodes koobaltisisaldust lugeda mitteküllaldaseks täisväärtusliku loomasöödla saamiseks.

\section{KIRJANDUS}

1. Методы определения микроэлементов. Изд. АН СССР, Москва 1950.

2. В ласюк П. А. и Л енден нк а я Л. Д., Содержание подвижных форм микроэлемента марганца в почзенных разновидностях Украинской ССР. «Почвоведение 1950 , № 6 .

3. Lillema, A., Eesti NSV mullastik. - Maaviljeluse käsiraamat. Tartu 1944.

4. В о й н а р А. О., Биологическая роль микроэлементов в организме животных и человека. Москва 1953.

5. Hirmo, E., Vaskväetise kasutamisest soomaadel. «Rahva Hääl» 28. apr. 1954.

6. R a id la, A., Kultuurkarjamaade rajamise ja kasutamise kogemusi turvasmuldadel. «Sotsialistlik Pōllumajandus» 1955 , nr. 1.

7. П ей в е Я. В., Микроэлементы в сельском хозяйстве нечерноземной полосы СССР. Изд. АН СССР, Москва 1954. 
8. Бахулин М. Д., Применение меди в качестве удобрения на торфяных почвах. В сб. Микроэлементы в жизни растеннй и животных. Изд. АН СССР, Москва 1952.

9. Ku u m, J., Soode kuivendamine ja kasutamine pōllumajanduses. Tallinn 1954.

10. Кедров-З ихман О. К., Розенберг Р. Е. и Протащик Н. Е., Действие кобальта и молибдена на сельскохозяйственные растення на дерново-подзолистых и торфяно-болотных почзах Белорусской ССР. Микроэлементы. Тезисы докладов Всесоюзного совещания по микроэлементам. Март 1955 года.

11. Берзи н Я. М., Значение кобальта и меди в кормлении сельскохозяйственных животных. В сб. Микроэлементы в жизни растений и животных. АН СССР, Москва 1952.

Eesti NSV Teaduste Akadeemia Taimekasvatuse Instituut

Saabus toimetusse

11. II 1956

\section{СОДЕРЖАНИЕ МИКРОЭЛЕМЕНТОВ В НЕКОТОРЫХ БОЛОТНЫХ ПОЧВАХ ЭСТОНСКОЙ ССР}

\section{Х. К. МИХЕЛЬСОН}

\section{Резюме}

Изучение содержания микроэлементов в почвах республики было начато в небольшом объеме Институтом растениеводства АН Эстонской ССР в 1952 году. Первоначально изучались только торфяно-болотные почвы массивов, которые намечалось осушить. Анализировались почвы 16 массивов болот, причем всего было изучено 50 почвенных разрезов.

При анализах определялось содержание в почвах меди, бора, марганца и кобальта. Анализами установленө, что в торфяно-болотных почвах валовое содержание меди в слое $0-40$ см колеблется в пределах от 0,5 до 11,0 мг на 1 кг почвы, содержание же доступной растениям меди (растворимой в 1 н. соляной кислоте) составляет от 0,1 до 1,4 мг, а в отдельных случаях до 3,5 мг на 1 кг почвы.

Содержание бора в болотных почвах колеблется в пределах от 0,2 до $27,6 \mathrm{mr}$, кобальта - от 0,1 до 1,0 мг (в отдельных случаях до 2,6 мг) на 1 кг почвы, а содержание марганца - от 0,002 до 0,14 процента. В почве одного из болотных массивов у основания склюна имелось очень много марганца - 0,6 процента, что, очевидно, связано с намывом илистых частиц минеральной почвы со склона и аккумуляцией марганца в торфяно-болотной почве.

Анализы торфяно-болотных почв и проведенные вегетационные опыты показывают, что в большинстве случаев содержание в них меди недостаточно для нормального развития многих сельскохозяйственных растений.

Так, например, вегетационными опытами, проведенными на торфе из массива Пыхяка (Пайдеский район) установлено, что при валовом содержании меди в 6,0 мг и усвояемой меди 1,6 мг на 1 кг почвы (pH 5,8) внесение медного удобрения обусловливало повышение урожая овса на $40,1 \%$.

На почве из района реки Амме (Тартуский район) при валовом содержании меди в 3,4 мг и усвояемой меди 1,2 мг на 1 кг почвы (pH 5,5) при внесении медных удобрений получена прибавка урожая в размере $19,3 \%$, а на почве массива болота в районе реки Ыхне южной Әстонии, где валовое содержание меди было равно 5,5 мг и усвояемой меди 3,0 мг на 1 кг почвы (pH 5,0) эффекта при внесении медного удобрения не получено. 
На тех почвах, где бора меньше 5 мг на 1 кг почвы, применение борного удобрения дает эффект. Удобрение марганцовыми удобрениями дает положительный результат на торфяно-болотных почвах, если марганца в них содержится менее 0,015 процента, что особенно резко выражено на болотах северной Әстонии, имеющих реакцию торфа близкую к нейтральной. Малое количество кобальта в болотных почвах является причиной недостаточного содержания этого элемента. в выращиваемых на торфяных почвах кормах.

Изучение содержания микроэлементов и опыты с применением микроудобрений на торфяно-болотных почвах продолжаются.

Институт растениеводства

Академии наук Әстонской ССР
Поступила в редакцию

11 II 1956

\section{DER GEHALT VON SPURENELEMENTEN IN EINIGEN MOORBÖDEN IN DER ESTNISCHEN SOWJETREPUBLIK}

\section{H. MICHELSON}

\section{Zusammenfassung}

Es ist eine Untersuchung über den Gesamtgehalt der wichtigsten Spurenelemente $\mathrm{Cu}, \mathrm{Mn}, \mathrm{Co}$ und $\mathrm{B}$ in einigen Moorgegenden durchgeführt worden. Der Gesamt-Cu-Gehalt in Tiefe von $0-40 \mathrm{~cm}$ beträgt durchschnittlich $0,5-11,0 \mathrm{mg} / \mathrm{kg}$, während der Gehalt an pflanzenverfügbarem $\mathrm{Cu}$ (bestimmt im $\mathrm{n} \mathrm{HCl}$ Auszuge) meist zwischen $0,1-1,4 \mathrm{mg} / \mathrm{kg}$ liegt und in einigen Moorböden auf $3,5 \mathrm{mg} / \mathrm{kg}$ steigt. Der Gesamtgehalt des Spurenelementes Bor liegt im Bereich von $0,2-27,6 \mathrm{mg} / \mathrm{kg}$, der MnGehalt meistenteils zwischen $0,002-0,14 \%$. Als Ausnahme ist im Sumpfgebiet des Flusses Ohne in Südestland ein Gesamt-Mn-Gehalt bis $0,6 \%$ festgestellt worden. Der Co-Gehalt der bisher untersuchten Bodenproben ist $0,1-1,0 \mathrm{mg} / \mathrm{kg}$, in Einzelfällen bis $2,6 \mathrm{mg} / \mathrm{kg}$. Berücksichtigt man, dass der Gehalt des pflanzenverfügbaren Co erheblich geringer ist, so ergibt sich, dass der Co-Gehalt der Moorböden nicht hinreicht, vollwertiges Viehfutter zu kultivieren.

Angestellte Gefässversuche an Hafer als Versuchspflanze zeigen, dass der Ertrag einiger Moorböden bei Zufuhr von Cu-Düngung nicht steigt. Diese Tatsache verlangt einer eingehenderen Aufklärung. Ist der Borgehalt unter $5 \mathrm{mg} / \mathrm{kg}$, so ist bei Zufuhr von B-Düngung Ertragssteigerung zu erwarten. Bei niedrigem Mn-Gehalt (unter 0,015\%) ist Mn-Düngung angezeigt, namentlich in Moorgebieten Nordestlands, wo der neutralen oder nahezu neutralen Bodenreaktion wegen die Verfügbarkeitsbedịngungen der Spurenelemente ungünstig sind. Ein Mn-Gehalt von 0,025$0,050 \%$ ist als genügend anzusehen, den Mn-Bedarf der Pflanzen zu befriedigen. Ist der Mn-Gehalt noch höher, - über 0,06\%, - so kann Mn-Düngung sogar fallende Erträge zur Folge haben.

Institut für Pflanzenbau

der Akademie der Wissenschaften der Estnischen SSR
Eingegangen am 11. Febr. 1956 